\title{
Pengaruh Kualitas Pelayanan Dan Kepercayaan Terhadap Loyalitas Konsumen Dengan Kepuasan Sebagai Variabel Mediasi (Studi Pada Ideo Photography di Semarang)
}

\author{
Kristian Agma Lambang Wibowo; MY.Dwi Hayu Agustini \\ email: kristianagma@gmail.com \\ Magister Manajemen, Fakultas Ekonomi dan Bisnis \\ Universitas Katolik Soegijapranata
}

\begin{abstract}
The purpose of this study was to determine the effect of service quality and trust on consumer loyalty with satisfaction as a mediating variable on Ideo Photography in Semarang. The population of this study is consumers who use Ideo Photography services, with unknown number of consumers. The sample of this study was 96 respondents. The sampling technique is purposive sampling. Data collection is done by distributing questionnaires through Google form. Data analysis techniques used multiple linear regression analysis. The results showed that: service quality significantly affects customer satisfaction, trust influences customer satisfaction, customer satisfaction affects customer loyalty. Service quality influences customer loyalty. Trust influences consumer loyalty. Service quality influences customer loyalty through customer satisfaction. Trust influences customer loyalty through customer satisfaction.
\end{abstract}

Keywords: Service quality, trust, customer satisfaction and customer loyalty.

\section{PENDAHULUAN}

Dalam menghadapi persaingan bisnis diera industri kreatif yang semakin ketat saat ini, banyak perusahaan penyedia jasa yang berorientasi pada konsumen yaitu dengan meningkatkan kepuasaan konsumen dalam menentukan pilihan. Hal ini sesuai dengan pernyataan Rofiah dan Wahyuni (2018) bahwa hal utama yang diprioritaskan oleh perusahaan yang bergerak dalam bidang pelayanan adalah kepuasan pelanggan agar dapat bertahan yang mengakibatkan peningkatan loyalitas untuk menguasai pasar. Perusahaan dituntut berusaha membuat pelanggan merasa puas dengan memberikan penawaran dan pelayanan yang lebih baik dengan mengembangkan strategi mempertahankan loyalitas konsumen melalui kualitas jasa.

Saat ini Ideo Photography tengah berupaya mempertahankan keunggulan bersaing diantara bisnis jasa fotografi di semarang. Berbagai usaha telah dilakukan Ideo 
Photography dalam meningkatkan pelayanan konsumen, diantaranya dengan didukung karyawan yang profesional dan berpengalaman yang mempunyai kompetensi dalam bidangnya. Hal yang melatar belakangi permasalahan, bahwa berbagai usaha yang dilakukan oleh Ideo Photography tidak diimbangi dengan peningkatan penjualan. Hasil survei di lapangan menunjukkan bahwa pada tahun 2014-2017, konsumen Ideo Photography mengalami penurunan rata-rata $8,40 \%$. Data ini didukung dengan fenomena di lapangan yang menunjukkan bahwa sebagian besar konsumen yang menggunakan jasa Ideo Photography adalah konsumen baru, sedangkan konsumen lama yang kembali menggunakan jasa Ideo Photography hanya sedikit. Hal ini mengindikasikan loyalitas konsumen dalam menggunakan jasa Ideo Photography mengalami penurunan.

Melihat uraian diatas dan fenomena yang terjadi pada Ideo Photography maka peneliti tergugah untuk melakukan penelitian dengan judul: "Pengaruh Kualitas Pelayanan Dan Kepercayaan Terhadap Loyalitas Konsumen Dengan Kepuasan Sebagai Variabel Mediasi (Studi Pada Ideo Photography di Semarang)".

\section{LANDASAN TEORI}

Perbedaan dari kenyataan dan harapan konsumen terhadap pelayanan yang didapat adalah kualitas pelayanan (Ratnasari dan Aksa, 2011). Usaha untuk memenuhi keinginan konsumen dan tepat dalam penyampaiannya untuk menyamai harapan dari konsumen merupakan definisi kualitas pelayanan (Tjiptono, 2011). Menurut Kotler dan Keller (2014), hal yang mengenai perilaku berbanding terhadap harapan dengan kinerja adalah kualitas pelayanan. Suryani (2013), menjelaskan penilaian dari konsumen berdasarkan dari apa yang dirasakan dan didapat berbanding dengan apa yang diharapkan oleh konsumen, dua hal yang menjadi dasar konsumen adalah layanan yang diterima dan diharapkan.

Melalui pengalaman beragam, konsumen memperoleh banyak kepercayaan mengenai produk, merek, dan objek lain di sekitarnya. Kunci untuk memahami sikap konsumen adalah mengidentifikasi dan mengerti dasar kepercayaan tersebut. Secara prinsip, konsumen dapat memiliki kepercayaan mengenai segala jenis dan tingkatan arti yang memiliki asosiasi dengan produk tertentu (Peter dan Olson, 2013). 
Menurut Kotler dan Keller (2014), perbandingan antara kinerja dan hasil yang dirasakan terhadap apa yang diharapkan adalah kepuasan konsumen. Peter dan Olson (2014), membandingkan antara kinerja dan ekspektasi konsumen dapat menimbulkan perasaan kecewa atau senang. Saat ini kebanyakan perusahaan yang mengarahkan kepuasaan konsumen sebagai bagian utama dalam tujuan perusahaan karena semakin sengitnya persaingan dan semakin banyaknya perusahaan baru yang fokus pada kebutuhan konsumen. Ini tergambar dari perusahaan sekarang yang berpegang kepada kepuasaan konsumen dalam visi misi perusahaan.

Loyalitas konsumen adalah pembelian ulang suatu merek secara konsisten (reguler) oleh konsumen (Tjiptono, 2011 dan Alma, 2013). Hal ini menunjukkan komitmen konsumen yang dipegang secara mendalam untuk membeli atau mendukung kembali produk atau jasa yang disukai dimasa depan (Kotler dan Keller, 2014). Loyalitas konsumen juga menunjukkan lamanya konsumen menggunakan didasarkan pada kebiasaan dan keinginan untuk tidak berpindah (Aaker, 2013).

Loyalitas konsumen sangat penting artinya bagi perusahaan untuk menjaga kelangsungan usahanya. Pada tahap berikutnya konsumen yang loyal tersebut akan memperluas loyalitas pada produk-produk lain buatan produsen yang bersangkutan sehingga konsumen loyal pada produsen atau perusahaan tertentu untuk selamanya (Tjiptono, 2011).

\section{KERANGKA PIKIR}

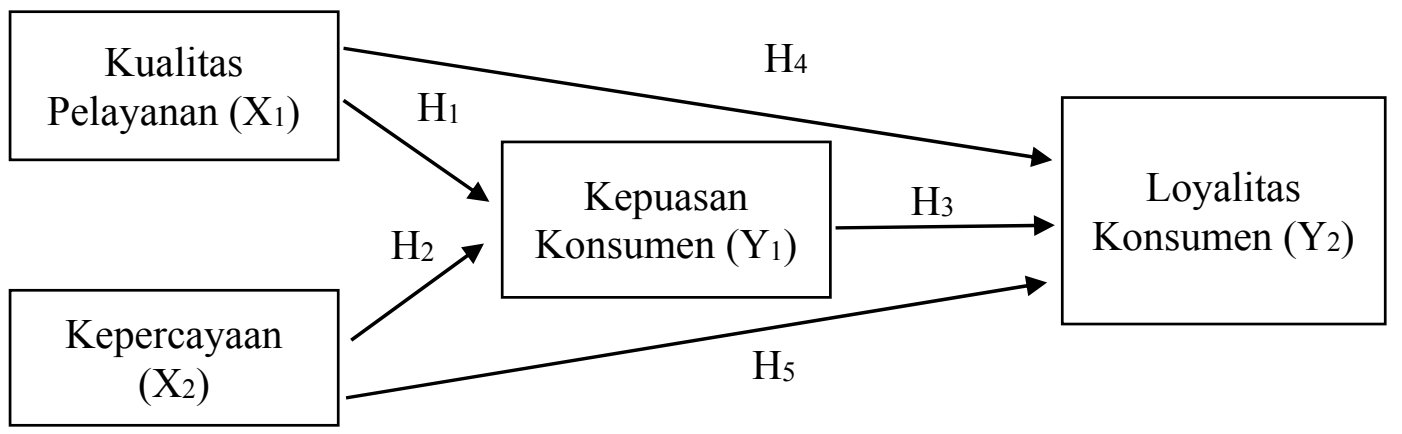

Gambar 1. Kerangka Pemikiran Teoritis 
JEMAP: Jurnal Ekonomi, Manajemen, Akuntansi, dan Perpajakan

\section{METODE PENELITIAN}

Populasi dalam penelitian ini adalah konsumen yang menggunakan jasa Ideo Photography, dengan jumlah konsumen tidak diketahui. Sampel pada penelitian ini adalah konsumen yang menggunakan jasa Ideo Photography dalam 2 tahun terakhir yaitu pada tahun 2017-2019. Jumlah sampel yang diambil dalam penelitian ini adalah 96 orang. Data sampel menggunakan teknik non acak yang pelaksanaannya menggunakan purposive sampel. Kriteria sampel dalam penelitian ini adalah konsumen yang menggunakan jasa Ideo Photography minimal 1 kali pemakaian jasa.

Alat pengumpulan data yang digunakan menggunakan kuesioner. Metode pengumpulan data dilakukan dengan 2 cara, yang pertama dengan menyebar lembar angket langsung ke rumah responden kedua dengan menyebar kuesioner melalui google form. Kuesioner diberikan kepada responden yang menggunakan jasa Ideo Photography dalam 2 tahun terakhir. Data terkumpul dianalisis dengan Path Analysis.

\section{ANALISIS DATA}

Tabel 1. Hasil Regresi Berganda Kualitas Pelayanan dan Kepercayaan Terhadap Kepuasan Konsumen.

\section{Coefficients $^{\mathrm{a}}$}

\begin{tabular}{|c|c|c|c|c|c|c|}
\hline & \multirow{2}{*}{ Model } & \multicolumn{2}{|c|}{$\begin{array}{l}\text { Unstandardized } \\
\text { Coefficients }\end{array}$} & \multirow{2}{*}{$\begin{array}{c}\begin{array}{c}\text { Standardized } \\
\text { Coefficients }\end{array} \\
\text { Beta }\end{array}$} & \multirow[t]{2}{*}{$\mathrm{t}$} & \multirow{2}{*}{ Sig. } \\
\hline & & B & Std. Error & & & \\
\hline \multirow{3}{*}{1} & (Constant) & 995 & ,483 & & 2,059 &, 042 \\
\hline & $\begin{array}{l}\text { Kualitas } \\
\text { Pelayanan }\end{array}$ & ,119 &, 030 & ,411 & 4,010 &, 000 \\
\hline & Kepercayaan & ,446 & ,091 - 1 & ,502 & 4,888 &, 000 \\
\hline
\end{tabular}

a. Dependent Variable: Kepuasan Konsumen

Sumber : Data Primer Diolah, 2019 
Berdasarkan dari hasil regresi maka dapat dibuat persamaan linear sebagai berikut: $\mathrm{Y}_{1}=0,995+0,119 \mathrm{X}_{1}+0,446 \mathrm{X}_{2}$

Persamaan regresi tersebut dapat diartikan sebagai berikut :Konstanta (a) $=0,995$, dapat diartikan apabila kualitas pelayanan dan kepercayaan dalam keadaan tetap maka kepuasan konsumen masih bernilai positif. Koefisien regresi kualitas pelayanan $\left(b_{1}\right)=$ 0,119 , nilai positif yang didapat menunjukkan bahwa setiap ada peningkatan kualitas pelayanan maka akan meningkatkan kepuasan konsumen. Koefisien regresi kepercayaan $\left(b_{2}\right)=0,446$, nilai positif yang didapat menunjukkan bahwa setiap ada peningkatan kepercayaan maka akan meningkatkan kepuasan konsumen.

Tabel 2.Hasil Regresi Berganda Kualitas Pelayanan, Kepercayaan, dan Kepuasan Konsumen Terhadap Loyalitas Konsumen.

Coefficients $^{\mathrm{a}}$

\begin{tabular}{|c|c|c|c|c|c|c|}
\hline & \multirow{2}{*}{ Model } & \multicolumn{2}{|c|}{$\begin{array}{l}\text { Unstandardized } \\
\text { Coefficients }\end{array}$} & \multirow{2}{*}{$\begin{array}{c}\begin{array}{c}\text { Standardized } \\
\text { Coefficients }\end{array} \\
\text { Beta }\end{array}$} & \multirow[t]{2}{*}{$\mathrm{t}$} & \multirow[t]{2}{*}{ Sig. } \\
\hline & & B & Std. Error & & & \\
\hline \multirow{4}{*}{1} & (Constant) &, 329 & ,741 & & ,444 & ,658 \\
\hline & $\begin{array}{l}\text { Kualitas } \\
\text { Pelayanan }\end{array}$ & ,104 & ,048 & 207 & 2,161 & ,033 \\
\hline & Kepercayaan &, 345 & 154 & 222 & 2,245 &, 027 \\
\hline & $\begin{array}{l}\text { Kepuasan } \\
\text { Konsumen }\end{array}$ & ,920 & , 156 & ,528 & 5,916 &, 000 \\
\hline
\end{tabular}

a. Dependent Variable: Loyalitas Konsumen Sumber : Data Primer Diolah, 2019

Berdasarkan dari hasil regresi maka dapat dibuat persamaan linear sebagai berikut

$\mathrm{Y}_{2}=0,329+0,104 \mathrm{X}_{1}+0,345 \mathrm{X}_{2}+0,920 \mathrm{Y}_{1}$

Persamaan regresi tersebut dapat diartikan sebagai berikut Konstanta $(\alpha)=0,329$, dapat diartikan apabila kualitas pelayanan, kepercayaan dan kepuasan konsumen dalam 
JEMAP: Jurnal Ekonomi, Manajemen, Akuntansi, dan Perpajakan

keadaan tetap maka loyalitas konsumen masih bernilai positif. Koefisien regresi kualitas pelayanan $\left(b_{1}\right)=0,104$, nilai positif yang didapat menunjukkan bahwa setiap ada peningkatan kualitas pelayanan maka akan meningkatkan loyalitas konsumen. Koefisien regresi kepercayaan $\left(b_{2}\right)=0,345$, nilai positif yang didapat menunjukkan bahwa setiap ada peningkatan kepercayaan maka akan meningkatkan loyalitas konsumen. Koefisien regresi kepuasan konsumen $\left(b_{3}\right)=0,920$, nilai positif yang didapat menunjukkan bahwa setiap ada peningkatan kepuasan konsumen maka akan meningkatkan loyalitas konsumen.

Tabel 3. Hasil Uji t Kualitas Pelayanan dan Kepercayaan Terhadap Kepuasan Konsumen

\begin{tabular}{ccccc}
\hline Variabel & $\mathrm{t}$ & Sig. & $\mathrm{t}$ tabel & Hasil Uji \\
\hline Kualitas Pelayanan & 4,010 & 0,000 & 1,986 & Signifikan \\
\hline Kepercayaan & 4,888 & 0,000 & 1,986 & Signifikan \\
\hline
\end{tabular}

Sumber : Data Primer Diolah, 2019

Berdasarkan dari hasil uji t maka dapat dilakukan pengujian sebagai berikut : Pengaruh Kualitas Pelayanan Terhadap Kepuasan Konsumen. Hipotesis : Ho : kualitas pelayanan tidak berpengaruh terhadap kepuasan konsumen. Ha : kualitas pelayanan berpengaruh terhadap kepuasan konsumen. Penerimaan Hipotesis : Ho : diterima bila $t$ hitung $<\mathrm{t}$ tabel dan sig. $>0,05$. Ha: diterima bila $\mathrm{t}$ hitung $>\mathrm{t}$ tabel dan sig. $<0,05$.

Penentuan $\mathrm{t}$ tabel yaitu $=\mathrm{df}=\mathrm{n}-\mathrm{k}-1=96-2-1=93$ dan pada sig. $=0,05$ maka didapat $\mathrm{t}$ tabel dua sisi sebesar 1,986.

Hasil uji t kualitas pelayanan terhadap kepuasan konsumen mendapatkan $\mathrm{t}$ hitung $=4,010>\mathrm{t}$ tabel $=1,986$ dengan sig. $0,000<0,05$ sehingga menerima hipotesis yang menyatakan kualitas pelayanan berpengaruh terhadap kepuasan konsumen. Pengaruh Kepercayaan Terhadap Kepuasan Konsumen. Hipotesis : Ho : kepercayaan tidak berpengaruh terhadap kepuasan konsumen. Ha : kepercayaan berpengaruh terhadap 
kepuasan konsumen. Penerimaan Hipotesis Ho : diterima bila $\mathrm{t}$ hitung $<\mathrm{t}$ tabel dan sig. $>0,05$. Ha: diterima bila $\mathrm{t}$ hitung $>\mathrm{t}$ tabel dan sig. $<0,05$. Penentuan $\mathrm{t}$ tabel yaitu $=\mathrm{df}$ $=\mathrm{n}-\mathrm{k}-1=96-2-1=93$ dan pada sig. $=0,05$ maka didapat $\mathrm{t}$ tabel dua sisi sebesar 1,986 .

Hasil uji t kepercayaan terhadap kepuasan konsumen mendapatkan $\mathrm{t}$ hitung $=4,888$ $>\mathrm{t}$ tabel $=1,986$ dengan sig. $0,000<0,05$ sehingga menerima hipotesis yang menyatakan kepercayaan berpengaruh terhadap kepuasan konsumen.

Tabel 4.Hasil Uji t Kualitas Pelayanan, Kepercayaan, dan Kepuasan Konsumen Terhadap Loyalitas Konsumen.

\begin{tabular}{ccccc}
\hline Variabel & $\mathrm{t}$ & Sig. & $\mathrm{t}$ tabel & Hasil Uji \\
\hline Kualitas Pelayanan & 2,161 & 0,033 & 1,986 & Signifikan \\
\hline Kepercayaan & 2,245 & 0,027 & 1,986 & Signifikan \\
\hline $\begin{array}{c}\text { Kepuasan } \\
\text { Konsumen }\end{array}$ & 5,916 & 0,000 & 1,986 & Signifikan \\
\hline
\end{tabular}

Sumber : Data Primer Diolah, 2019

Pengaruh Kualitas Pelayanan Terhadap loyalitas Konsumen. Hipotesis Ho : kualitas pelayanan tidak berpengaruh terhadap loyalitas konsumen. Ha : kualitas pelayanan berpengaruh terhadap loyalitas konsumen. Penerimaan Hipotesis Ho : diterima bila $\mathrm{t}$ hitung $<\mathrm{t}$ tabel dan sig. $>0,05$. Ha: diterima bila $\mathrm{t}$ hitung $>\mathrm{t}$ tabel dan sig. $<0,05$. Penentuan $\mathrm{t}$ tabel yaitu $=\mathrm{df}=\mathrm{n}-\mathrm{k}-1=96-3-1=92$ dan pada sig. $=0,05$ maka didapat $\mathrm{t}$ tabel dua sisi sebesar 1,986. Hasil uji t kualitas pelayanan terhadap loyalitas konsumen mendapatkan $\mathrm{t}$ hitung $=2,161>\mathrm{t}$ tabel $=1,986$ dengan sig.0,033 $<0,05$ sehingga menerima hipotesis yang menyatakan kualitas pelayanan berpengaruh terhadap loyalitas konsumen. Pengaruh Kepercayaan Terhadap loyalitas Konsumen. Hipotesis Ho : kepercayaan tidak berpengaruh terhadap loyalitas konsumen. Ha : kepercayaan berpengaruh terhadap loyalitas konsumen. Penerimaan Hipotesis :Ho : diterima bila $\mathrm{t}$ hitung $<\mathrm{t}$ tabel dan sig. $>0,05$. Ha: diterima bila $\mathrm{t}$ hitung $>\mathrm{t}$ tabel dan sig. $<0,05$. Penentuan $\mathrm{t}$ tabel yaitu $=\mathrm{df}=\mathrm{n}-\mathrm{k}-1=96-3-1=92$ dan pada sig. $=0,05$ maka 
JEMAP: Jurnal Ekonomi, Manajemen, Akuntansi, dan Perpajakan

didapat $\mathrm{t}$ tabel dua sebesar 1,986. Hasil uji t kepercayaan terhadap loyalitas konsumen mendapatkan $\mathrm{t}$ hitung $=2,245>\mathrm{t}=1,986$ dengan sig. $0,027<0,05$ sehingga menerima hipotesis yang menyatakan kepercayaan berpengaruh terhadap loyalitas konsumen.

Pengaruh Kepuasan Konsumen Terhadap loyalitas Konsumen. Hipotesis : Ho : kepuasan konsumen tidak berpengaruh terhadap loyalitas konsumen. Ha : kepuasan konsumen berpengaruh terhadap loyalitas konsumen. Penerimaan Hipotesis :Ho : diterima bila $\mathrm{t}$ hitung $<\mathrm{t}$ tabel dan sig. $>0,05$. Ha: diterima bila $\mathrm{t}$ hitung $>\mathrm{t}$ tabel dan sig. $<0,05$. Penentuan $\mathrm{t}$ tabel yaitu $=\mathrm{df}=\mathrm{n}-\mathrm{k}-1=96-3-1=92$ dan pada sig. $=0,05$ maka didapat $t$ tabel dua sebesar 1,986. Hasil uji t kepuasan konsumen terhadap loyalitas konsumen mendapatkan $\mathrm{t}$ hitung sebesar 5,916 $>\mathrm{t}$ tabel 1,986 dengan sig. 0,000<0,05 sehingga menerima hipotesis yang menyatakan kepuasan berpengaruh terhadap loyalitas konsumen. Uji F digunakan untuk menguji model regresi. Model akan diuji dengan menggunakan tingkat signifikansi 0,05 .

Tabel 5. Hasil Uji F Kualitas Pelayanan dan Kepercayaan Terhadap Kepuasan Konsumen

\begin{tabular}{|c|c|c|c|c|c|c|}
\hline \multicolumn{7}{|c|}{ ANOVA $^{a}$} \\
\hline & Model & $\begin{array}{l}\text { Sum of } \\
\text { Squares }\end{array}$ & $\mathrm{df}$ & Mean Square & $\mathrm{F}$ & Sig. \\
\hline \multirow{3}{*}{1} & Regression & 362,847 & 2 & 181,423 & $\begin{array}{r}170,2 \\
36\end{array}$ &, $000^{\mathrm{b}}$ \\
\hline & Residual & 99,111 & 93 & 1,066 & & \\
\hline & Total & 461,958 & 95 & & & \\
\hline
\end{tabular}

a. Dependent Variable: Kepuasan Konsumen

b. Predictors: (Constant), Kepercayaan, Kualitas Pelayanan

Sumber : Data Primer Diolah, 2019

Pengaruh Kualitas Pelayanan dan Kepercayaan Terhadap Kepuasan Konsumen. Hipotesis : Ho : kualitas pelayanan dan kepercayaan tidak berpengaruh terhadap kepuasan konsumen. Ha kualitas pelayanan dan kepercayaan berpengaruh terhadap kepuasan konsumen. Penerimaan Hipotesis Ho : diterima bila F hitung $<$ F tabel dan sig. 
$>0,05$. Ha: diterima bila $\mathrm{F}$ hitung $>\mathrm{F}$ tabel dan sig. $<0,05$. Penentuan $\mathrm{F}$ tabel yaitu $=\mathrm{df1}$ $=\mathrm{k}=2$ dan $\mathrm{df} 2=\mathrm{df}=\mathrm{n}-\mathrm{k}-1=96-2-1=93$ pada sig. $=0,05$ maka didapat $\mathrm{F}$ tabel sebesar 3,094. Hasil F hitung $=170,236>\mathrm{F}$ tabel $=3,094$ dan sig. $0,000<0,05$. Dengan hasil ini maka menerima model regresi antara kualitas pelayanan dan kepercayaan terhadap kepuasan konsumen.

Tabel 6. Hasil Uji F Kualitas Pelayanan, Kepercayaan, dan Kepuasan Konsumen Terhadap Loyalitas Konsumen

\begin{tabular}{llllrrr}
\multicolumn{7}{c}{ ANOVA $^{\text {a }}$} \\
\hline \multirow{2}{*}{ Model } & $\begin{array}{l}\text { Sum of } \\
\text { Squares }\end{array}$ & df & Mean Square & F & Sig. \\
\hline \multirow{3}{*}{1} & Regression & 1181,512 & 3 & 393,837 & $\begin{array}{r}164,15 \\
3\end{array}$ &, $000^{\text {b }}$ \\
\cline { 2 - 6 } & Residual & 220,727 & 92 & 2,399 & & \\
\cline { 2 - 7 } & Total & 1402,240 & 95 & & & \\
\hline
\end{tabular}

a. Dependent Variable: Loyalitas Konsumen

b. Predictors: (Constant), Kepuasan Konsumen, Kualitas Pelayanan, Kepercayaan

Sumber : Data Primer Diolah, 2019

Pengaruh Kualitas Pelayanan, Kepercayaan, dan Kepuasan Konsumen Terhadap Loyalitas Konsumen. Hipotesis Ho : kualitas pelayanan, kepercayaan, dan kepuasan konsumen tidak berpengaruh terhadap loyalitas konsumen. Ha : kualitas pelayanan, kepercayaan, dan kepuasan konsumen berpengaruh terhadap loyalitas konsumen. Penerimaan Hipotesis : Ho : diterima bila $\mathrm{F}$ hitung $<\mathrm{F}$ tabel dan sig. $>0,05$. Ha: diterima bila $\mathrm{F}$ hitung $>\mathrm{F}$ tabel dan sig. $<0,05$. Penentuan $\mathrm{F}$ tabel yaitu $=\mathrm{df} 1=\mathrm{k}=3$ dan $\mathrm{df} 2=\mathrm{df}$ $=\mathrm{n}-\mathrm{k}-1=96-3-1=92$ pada sig. $=0,05$ maka didapat $\mathrm{F}$ tabel sebesar 2,704. Hasil $\mathrm{F}$ hitung $=164,153>\mathrm{F}$ tabel $=2,704$ dan sig. $0,000<0,05$. Dengan hasil ini maka menerima model regresi kualitas pelayanan, kepercayaan, dan kepuasan konsumen terhadap loyalitas konsumen. 
Uji Sobel Kualitas Pelayanan Terhadap Loyalitas Konsumen Melalui Kepuasan Konsumen Sebagai Variabel Mediasi. Berdasarkan dari efek mediasi dapat dijelaskan bahwa pengaruh langsung kualitas pelayanan terhadap loyalitas konsumen sebesar 0,207. Sementara untuk pengaruh tidak langsung dapat dilihat dari pengaruh kualitas pelayanan terhadap kepuasan konsumen sebesar 0,411 dan baru kemudian kepuasan konsumen terhadap loyalitas konsumen sebesar 0,528 , nilai ini kemudian dikalikan yaitu $0,411 \mathrm{x}$ $0,528=0,217$. Hasil efek tidak langsung terlihat lebih besar dibanding efek langsung sehingga kualitas pelayanan cenderung berpengaruh tidak langsung terhadap loyalitas konsumen melalui kepuasan konsumen sebagai variabel mediasi.

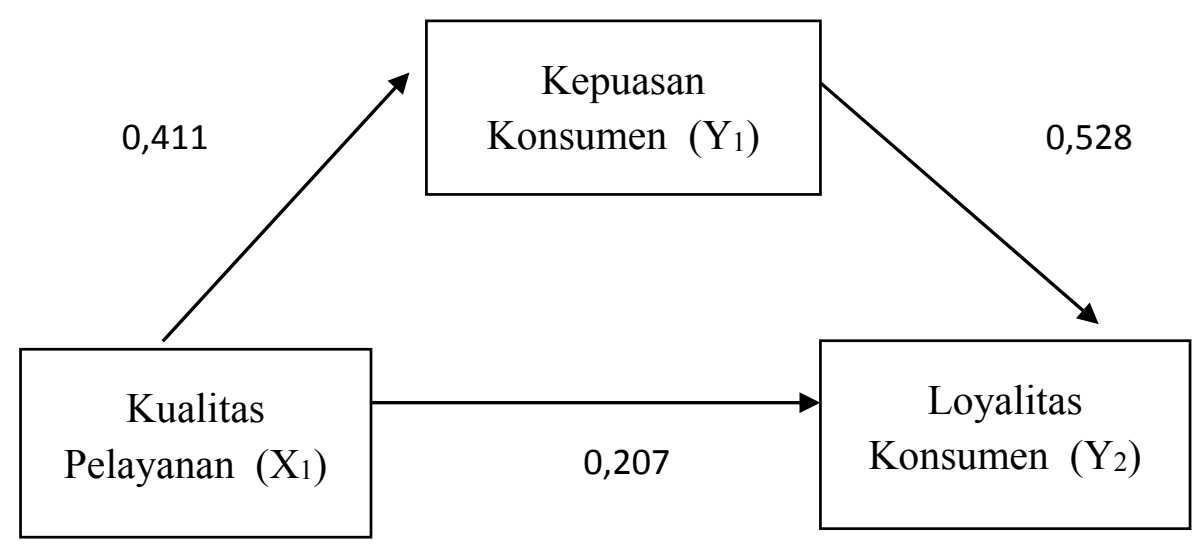

\section{Gambar 2. Pengaruh kualitas pelayanan terhadap loyalitas konsumen melalui kepuasan konsumen sebagai variabel mediasi.}

Berikutnya berdasarkan gambar 3, dari efek mediasi dapat dijelaskan bahwa pengaruh langsung kepercayaan terhadap loyalitas konsumen sebesar 0,222. Sementara untuk pengaruh tidak langsung dapat dilihat dari pengaruh kepercayaan terhadap kepuasan konsumen sebesar 0,502 dan baru kemudian kepuasan konsumen terhadap loyalitas konsumen sebesar 0,528 , nilai ini kemudian akan dikalikan yaitu $0,502 \times 0,528$ $=0,265$. Hasil efek tidak langsung terlihat lebih besar dibanding efek langsung sehingga kepercayaan cenderung berpengaruh tidak langsung terhadap loyalitas konsumen melalui kepuasan konsumen sebagai variabel mediasi. 


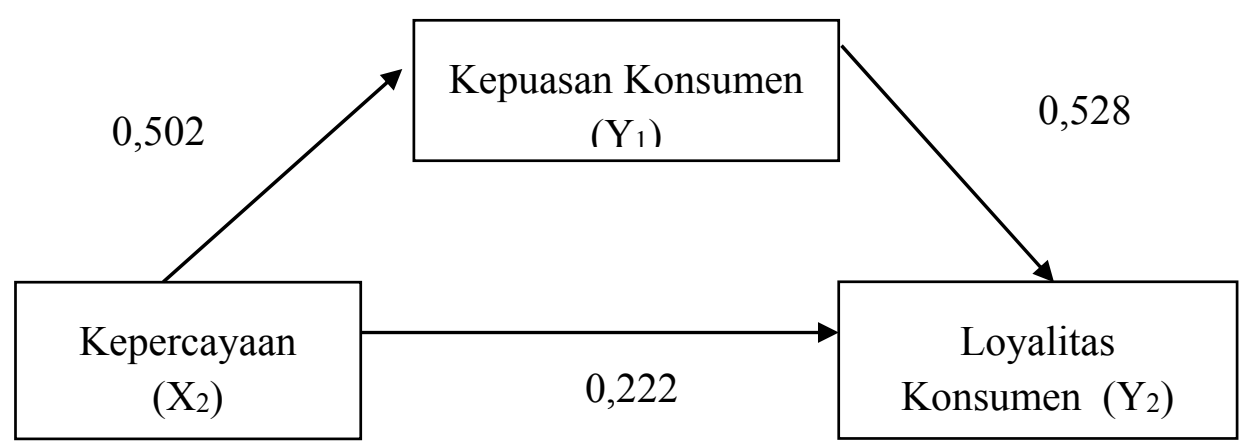

Gambar 3. Analisis Mediasi Kepercayaan Terhadap Loyalitas Konsumen Melalui Kepuasan Konsumen Sebagai Variabel Mediasi

Sumber : Data Primer Diolah, 2019

\section{HASIL DAN PEMBAHASAN}

Berdasarkan hasil penelitian yang telah diuraikan pada bab sebelumnya, dapat disimpulkan: Hasil analisis berganda diperoleh bahwa untuk variabel kualitas pelayanan terhadap kepuasan konsumen menunjukan nilai koefisien positif sebesar 0,119 dan diperoleh hasil $\mathrm{t}$ hitung $=4,010>\mathrm{t}$ tabel $=1,986$ dengan sig. $0,000<0,05$ sehingga menerima hipotesis yang menyatakan kualitas pelayanan berpengaruh terhadap kepuasan konsumen.

Hasil analisis berganda diperoleh bahwa untuk variabel kepercayaan terhadap kepuasan konsumen menunjukan nilai koefisien positif sebesar 0,446 dan diperoleh hasil $\mathrm{t}$ hitung $=4,888>\mathrm{t}$ tabel $=1,986$ dengan sig. $0,000<0,05$ sehingga menerima hipotesis yang menyatakan kepercayaan berpengaruh terhadap kepuasan konsumen.

Hasil analisis berganda diperoleh bahwa untuk variabel kepuasan konsumen terhadap loyalitas konsumen menunjukan nilai koefisien positif sebesar 0,920 dan diperoleh hasil $\mathrm{t}$ hitung $=5,916>\mathrm{t}$ tabel $=1,986$ dengan sig. $0,000<0,05$ sehingga menerima hipotesis yang menyatakan kepuasan konsumen berpengaruh terhadap loyalitas konsumen.

Hasil analisis berganda diperoleh bahwa untuk variabel kualitas pelayanan terhadap loyalitas konsumen menunjukan nilai koefisien positif sebesar 0,104 dan diperoleh hasil $\mathrm{t}$ hitung $=2,161>\mathrm{t}$ tabel $=1,986$ dengan sig.0,033 $<0,05$ sehingga 
menerima hipotesis yang menyatakan kualitas pelayanan berpengaruh terhadap loyalitas konsumen.

Hasil analisis berganda diperoleh bahwa untuk variabel kepercayaan terhadap loyalitas konsumen menunjukan nilai koefisien positif sebesar 0,345 dan diperoleh hasil $\mathrm{t}$ hitung $=2,245>\mathrm{t}$ tabel $=1,986$ dengan sig. $0,027<0,05$ sehingga menerima hipotesis yang menyatakan kepercayaan berpengaruh terhadap loyalitas konsumen.

Hasil uji sobel menunjukkan kualitas pelayanan berpengaruh terhadap loyalitas konsumen melalui kepuasan konsumen sebagai variabel mediasi dengan diperoleh hasil Z sebesar 3,29 $>1,98$ dan sig $0,000<0,05$.

Hasil uji sobel menunjukkan kepercayaan berpengaruh terhadap loyalitas konsumen melalui kepuasan konsumen sebagai variabel mediasi dengan diperoleh hasil Z sebesar 3,77 > 1,98 dan sig $0,000<0,05$.

\section{SARAN}

Berdasarkan hasil penelitian, maka saran yang diberikan sebagai berikut: Ideo Photography sebaiknya membuat standard operating procedure dalam memberikan pelayanan kepada konsumen, hal ini berdasarkan dari nilai terendah yang di berikan responden pada pernyataan kecepatan menangani pengerjaan foto. Konsumen merasa pelayanan dalam kecepatan foto di Ideo Photography masih kurang, faktor tersebut tidak membuat konsumen untuk kembali menggunakan jasa Ideo Photography. Karena kebutuhan konsumen pada dasarnya adalah ingin mendapatkan kualitas pelayanan yang baik dan sesuai dengan harapan konsumen. Oleh karena itu, hendaknya Ideo Photography lebih fokus untuk membuat standard operating procedure, dengan adanya standart operating procedure, Ideo Phtography dapat mengontrol pekerjaan dari awal sampai akhir. 
JEMAP: Jurnal Ekonomi, Manajemen, Akuntansi, dan Perpajakan

\section{DAFTAR PUSTAKA}

Aaker, David. 2013. Manajemen Pemasaran Strategis. Jakarta : Salemba Empat.

Alma, Buchari. 2013. Manajemen Pemasaran dan Pemasaran Jasa. Edisi Revisi. Bandung : CV. Alfabeta.

Daryanto. 2013. Sari Kuliah Manajemen Pemasaran. Cetakan II. Januari 2013. Bandung : PT. Sarana Tutorial Nurani Sejahtera.

Ghozali, Imam. 2016. Aplikasi Analisis Multivariate Dengan Program SPSS IBM SPSS 23. Cetakan Kedelapan. Semarang : Badan Penerbit Universitas Diponegoro.

Ginting, Nembah F. Hartimbul. 2012. Manajemen Pemasaran. Cetakan 2. Bandung : Yrama Widya.

Kotler, Philip dan Kevin Lane Keller. 2014. Manajemen Pemasaran. Edisi Ketigabelas. Jilid 1. Jakarta : Erlangga.

Peter, J. Paul dan Jerry C. Olson. 2013. Perilaku Konsumen dan Strategi Pemasaran. Buku 1. Edisi 9. Jakarta : Salemba Empat.

Peter, J. Paul dan Jerry. C. Olson. 2014. Perilaku Konsumen dan Strategi Pemasaran. Buku 2. Edisi 9. Jakarta : Salemba Empat.

Ratnasari, Ririn Tri dan Mastuti Aksa. 2011. Manajemen Pemasaran Jasa. Bogor : Ghalia Indonesia.

Siregar, Syofian. 2013. Metode Penelitian Kuantitatif : Dilengkapi Perhitungan Manual \& SPSS. Edisi Pertama. Cetakan ke 1. Jakarta : Kencana Prenada Media Group.

Suryani, Tatik 2013. Perilaku Konsumen di Era Internet. Implikasinya pada Strategi Pemasaran. Edisi Pertama. Cetakan Pertama. Yogyakarta : Graha Ilmu.

Tjiptono, Fandy. 2011. Pemasaran Jasa. Yogyakarta : Bayumedia Publishing.

Umar, Husein. 2013. Metode Penelitian untuk Skripsi dan Tesis Bisnis. Edisi Kedua. Cetakan Keduabelas. Jakarta : PT. Raja Grafindo Persada. 